\title{
The Workout: The Phenomenology of Training
}

\author{
Heather Devine \\ University of Alberta
}

"I train three times a week."

"I work out regularly."

"I'm taking fitness classes."

"I get a lot of exercise."

"I practise for an hour a day."

"Training. Practice. Exercise. Fitness. Working out." What do these terms imply? Do I train when I practice an activity? Do I "work out" when I exercise? What is the essence of intentional physical exercise? What is it like for me?

It's time to go swimming. I don't stop to talk, I don't walk slowly, I walk as fast as I can down the stairs, removing my wallet with my I.D. card and my token as I leave the building and go to the pool. I toss my I.D. and token on the counter, the attendant and I exchange smiles as she passes me my towel and I.D. bracelet. I don't stop to talk; I walk into the women's shower room, unzipping my jacket as I walk to my locker. I spin the lock quickly, as I simultaneously shed clothing and pull swimming paraphernalia from my locker-warmup jacket, goggles, cap, bathing suit, and shampoo.

I put my swimsuit on; it is tense, tight, outside of the water. It cuts across the flesh of my buttocks and digs into my shoulders. It is not an unpleasant feeling, in that it causes discomfort or pain, but it causes me to instinctively pull down the rear portion of my bathing suit. I'm on land; modesty prevails.

I go to the bathroom. I urinate, wash my hands, and place my goggles around my neck, looking into the mirror. I am aware of other women around me, in other costumes and states of undress, yet my eyes are riveted to my own form reflected in the mirror as I sleepwalk through my preparations.

This solitude is important to me, these moments by myself. I need to be silent, I need to put my bathing suit on exactly the same way, I need to change my clothes at the same bench, I need not to have to think.

I slip on my warmup jacket, grab my cap, goggles, towel, and shampoo, and walk out the door towards the west pool. I am conscious of a 
chill around my legs, I feel a sudden surge of self-consciousness as I walk past fully-clothed people; I feel freakish outside the water when I'm in my swimming clothes. I quickly enter the women's corridor of the west pool; my pace slows to a normal walk. Relief. The smell of chlorine is pervasive, but it is familiar; it envelops me, makes me feel I belong. I am drawn down the corridor. I pad silently along the matting, drawn like a child to the doors at the end. But before I enter I go to the showers. I look into the mirror once more. I look nowhere else. I take my cap and slowly pull it over my head. I tuck away the stray bits that poke out. I look into my eyes-the only part of me left. I'm not me anymore; I am eyes and nose and mouth and body. I take off my warmup jacket and flex my shoulders in front of the mirror-sometimes to warm up, sometimes because I just like seeing them. I see the bulge of my legs, the lean strips of muscle on the inside of my thighs, the smooth sweep of my leg muscles as they move to the curve of my buttocks - no fat-no bulges-sleek, like a racehorse. My arms hang loosely at my sides, the hands delicate, the lower arms spare, lean, corded with muscle, the upper arms relaxed, the biceps slightly curved. I put my hand on my hip;I watch the muscles tremble, move into place, the biceps flatten with tension. A wave of pleasure washes over me. I flex my arm. The bicep moves into a proper muscle, a good muscle! I look again at myself in the mirror. My shoulders are curved, wide, the muscles ripple, my legs are strong saplings-it is a hard body ... too hard? My eyes stare beseechingly into the mirror, but just for a moment. Yes, the hardness is there, the toughness is there ... and then I feel the strength. I know, deep inside me, that every day I come for that strength, that thrill of it running through my arms and legs, that independence, that autonomy, that need to imprint myself on something touchable, real, concrete, to hold onto my physical being as I get sucked away by the riptides, pulled and prodded and knocked off my feet by all those things that are stronger than me. I need to own myself for a few short minutes.

I grab my stuff and walk towards the pool. I look for a place to put my things; why I look I don't know; I always put my things in the same place, in a little cranny underneath an overturned canoe-my spot. I move deliberately-it is like making an entrance into the scene of a play-I've done this entrance so many times before, yet I'm not really conscious of others-if I hear the applause of othersit's one hand clapping ... my hand.

I approach the pool, not looking at the edge of the pool nearest to me, but at the other end. I love this moment, the pool surface unmarred-it waits for me to make my mark. I stand legs parted at the end of the pool, my legs astraddle the black line stretching to the end of the pool, my horizon, my lane... I feel like the Colossus looking over Rhodes for that one moment-my harbour, my kingdom, peaceful before the rabble comes. 
My eyes shift their gaze to the clock. My index finger goes to my mouth; I moisten it with spittle and rub the insides of my goggles, still eyeing the clock. I bend down and enter the water feet first. There is a momentary shock as the cold hits my diaphragm-I'm in.

I put my goggles on, taking care to fit them tightly around my eyesnot too tightly or they will cause too much pressure and discomfort, but not too loose-I can feel a space! I press and wiggle and adjust the cap and goggles until I can feel that grip, that suction around the eyeballs, that - fit.

Now I'm ready. I look at the clock-my gaze darts towards the end of the pool, my foot gropes the wall-I push off!

I stroke deliberately, rhythmically, down the pool. My breathing is regular, relaxed. My pulling and kicking is strong, steady, effortless. My first length is euphoric - there is no sense of tiredness. I own my space, I feel masterful, in total control. ... I reach the end-I grab the wall, almost viciously-my feet swing up-my arm lifts and I open my mouth in a wide snarl to grab the air as my torso twists around and my legs push the wall for that mute glide until I break the surface once again and pull the water with my arms. My shoulders move purposefully-I will not break my rhythm!

I continue down the pool ... stroke, kick, pull, reach-the-end, legsup, push, break, pull, pull, pull . . . length number twelve ... the ease has worn off ... a tiny frown of concentration creases my consciousness as the fatigue creeps in ... twenty-five ... it's business as usual. ... I am conscious of the placement of my arms and legs, the position of my elbows as I lift my arms out of the water ... boring ... why am I doing this? ... sigh ... My arm clips the water as I bring it forward for the downward pull. Dammit! ... shape up. ... My whole being tenses, I'm on task again, no more carelessness-move those arms, MOVE! I concentrate on getting my elbows clear of the watermake a nice stroke... I increase my rhythm-I count-1-2-1-2-1-2-12-1-2-1-2-1-2-1-2 as each arm enters the water 1-2-1-2-1-2 I'm coming to the end-I slow my rhythm so my left arm will grab the edge as I bring up my legs and push off-glide-slow down, and kick, and pull, kick, pull, pull, pull. Contentment seeps slowly through the inside of my head - that's where I feel it-a warmness, a tranquility, a peaceful spot right in the middle of my brain as my arms and legs flail and the water churns around me. There's a calm in the eye of my storm, and as my limbs thrash through the water my mind begins to drift ... the sounds of the pool-the echoing voices, the radio, the thump of the springboards, the muffled splashes all meld into a low hummmmmmm. .. . A wave in my mouth shocks me into alertness. ... The pool-my lane! is full of swimmers. A faint glimmer, a vague anxiety begins to creep into my mind. I continue to swim, but a wariness - vigilance - has broken my reverie - are these people going to interfere with me? 
There is a person in front of me, a woman. She is overweight, her legs move sluggishly, her breathing is labored. There is a momentary flash of anger-she has no business here! This is the fast lane! My attention shifts to the water. I shift my gaze beneath the surface and look to her left_no bodies coming my way-I cut to her left and slice by her, moving my arms quickly, precisely, not kicking, but just enough to get by, not interfering with her movement but just enough so I can get well ahead. I pull and kick hard to the edge and push away quickly, leaving her behind. I glide with relief, and settle into my old rhythm, comfortable now that there is some free space around me.

A stab of dismay hits my throat. Another swimmer flashes by me. He knows what he's doing. I can tell. I lose my rhythm momentarily-I falter-I feel suddenly thick and slow. My breathing becomes more labored as I move my arms faster ... funny, I seem to be moving so slowly ... another wave hits me in the face-my stomach churns and I can feel the vomit in my throat, and then in my mouth. Instinctively, convulsively, I clamp my mouth shut and swallow. I run my tongue over my teeth and suck some water into my mouth in mid-stroke, rinsing and swallowing ... I continue swimming. . . It just occurs to me that I have just been physically ill and that normally I would have been extremely upset, crying even. . . I I ponder this revelation as I continue down the pool . . . forty-five ... forty-six ... forty-seven ... I've got my second wind now ... oddly enough, it's just me and this guy, this other swimmer. There are others, but somehow they don't matter.... I sense a bond, a force drawing me to this swimmer-I feel a compulsion, an itch to keep his pace, to narrow the gap. He is a half-length ahead. I see him reach the end ... is he quitting? I stroke hopefully ... as I near the end he leaves ... I fight to close the gap but still there is that half-length, that distance, that I fight to close ... I'm gaining on him-he's gone again! . . He's teasing me . . .OK, hotshot ... forty-nine ... fifty . . . I can feel my strokes getting stronger ... fifty-three ... fifty-four . . f fifty-five ... fifty-six . . . the pace is increasing . . . fifty-seven, fifty-eight, fiftynine-I'm breathing in gasps ... sixty, sixty-one, sixty two . . my hands are stretching, grabbing, pulling, my head turns and I frantically grab the air ... sixty-three, sixty-four, sixty-five ... my throat is aching, all I can see is a foggy blur ... sixty-six, sixty-seven, sixtyeight ... my face feels hot, my mouth is dry, I want to slow down, to suck some water into my mouth, I need a drink so badly . . . sixtynine, seventy-I'm plotting every move of my arm, every tactic, how strong do I pull, how many strokes, let's catch him! . . seventy-one ... I'm getting closer ... I move in ... his air bubbles are hitting my face ... I pull harder ... the gap is closing ... his feet are churning in front of my nose-the bubbles are streaming around my face and bouncing off my goggles... I've got him! A hand grips my shoulder. I'm being stopped? . . I I stop and stagger to my feet . . I I peer through the fog in my goggles in confusion.... It was going so well ... 
"We have to move to the other pool ... good thing, too. I needed a rest."

I stroke thoughtfully back to my edge of the pool. My lengths are finished now ... no crashing, no pulling, just gliding slowly along.... I don't feel exhausted at all anymore, I don't even feel like I've gone swimming at all ... I touch the edge, I look back ... I don't want to get out now ... all my work is done; now I want to swim for me ... I look down the pool, and push off, hard ... I sprint, as hard as I can ... I watch the lane lines move faster and faster towards me as my arms move faster, faster, faster, faster, until — the edge.

I stop. I remove my goggles, my eyes blink-I'm me again.

I walk slowly away from the pool, my legs wobbly, my mind befuddled and pleasantly dizzy from fatigue. I stagger to the showers, where I begin to slowly peel away my swimming clothes. I stand under the shower naked, slightly confused, my eyes staring blankly around me like a baby who has just woken from a nap. I feel somehow innocent, childlike-new. There is a sense of humility, a sense of awe and wonder. I just did a mile! I ponder this as I dry myself in an abstracted way ... huh!.... in a way it's a miracle.

\section{Why Do Athletes Train?}

When we train we are guiding ourselves, drawing ourselves along the proper path, often against our natural inclinations. When we "work out" we bring about fitness through labor and exertion, we remake ourselves into healthy individuals through repetitious activity. When we exercise we work continuously, cultivating our actions and through these actions we prune-train our bodies into something. But what? Into an efficient machine? Into a thing of beauty? And when does this transformation occur?

What does it mean to be "fit?" Is fitness merely a state of good physical health, or is it something more? The Latin word synonymous with fitness is habilitas, or suitability. This word is closely related to the Latin habeo meaning "to possess, have power over." To stay in good cardiovascular condition a person needs a minimum of twenty minutes of aerobic exercise three times a week. But many people who are serious about training exercise on a much more regular basis and for far greater lengths of time. Surely they have "power" over their bodies; why maintain such a rigorous training program? Could they, perhaps, be seeking another "power," another sense of ownership?

What does it mean to have a beautiful body? The bodies of athletes who train regularly and rigorously are not "beautiful" in the conventional sense of the term. The weightlifter who possesses grotesquely enlarged muscles is attractive primarily to aficionados of weightlifting. The emaciated runner with enlarged leg muscles out of proportion to the rest of his body, the female swimmer with large, 
bowed shoulders, the ballet dancer with feet gnarled from the strain of supporting the body-is this beautiful?

Some people would say "yes." But why? What makes emaciation and physical deformity a virtue amongst athletes and a stigma in the rest of society? What sets the athlete apart from the non-athlete in his perception of beauty? Can we honestly say that the athlete trains to achieve the societal standards of beauty? Yet this is a common rationale for engaging in physical exercise; is it the only rationale?

Training is also lauded for its tranquilizing effect. Many people train as a respite from the hurly-burly of everyday life. But swimming in a crowded pool is hardly conducive to calm and relaxation. Neither is the physical stress that accompanies exercise-torn ligaments, tendonitis, muscle spasms, stress fractures-the list is endless. People who train for extended periods of time generally sustain some sort of discomfort or injury along the way, yet, oddly enough, these minor setbacks tend to spur most athletes on to even greater efforts as soon as they are physically capable of training again.

The discipline of training-its "character-building" qualities-has been used since the time of the ancient Greeks (Leonard, 1974) as a rationale for the inclusion of physical education-particularly team sports-in the school curriculum.

As Leonard (1974) points out, "The structure and intent of a culture's sports and games both reflect and help shape the structure and intent of the culture itself." Physical education has become highly technical. We understand that the performance of the childathlete is measured in quantitative, rather than experiential, terms. The child who is incapable of measuring up to arbitrary, externally established standards of performance, comes eventually to view his body as an alien object, an enemy - a thing separate and apart. This writer would ask: Can a child derive any spiritual benefit from sport when she is made to feel that her body functions inadequately?

Sports in the school system are a microcosm of society: competitive, institutionalized, and preoccupied with "victory." "Making the team" in high school is analagous to becoming "a member of the board." Success in athletics has become a metaphor for success in the "real world," at least in the minds of those who plan and implement physical education curricula in the school system. And, inevitably, the "character-building" quality of sport becomes corrupted and ultimately obscured. For the natural athlete, school sports becomes an idyllic - albeit spiritually narrowing and intellectually stifling-experience. For the individual who is not athletically adept, or who does not have the "requisite" body type for success at sports, the experience of physical education can be an exercise in misery. 
The purpose of this discussion is not to denigrate one's motivations for physical training, or to discount the benefits of training, which are considerable. Unfortunately, when we allow the phenomenon of training to be defined within such limiting parameters, we deprive ourselves of all that the lived-world of training actually has to offer. Physical training has the potential to be a transcendental experience, as many athletes will attest. However, much of the spiritual aspect of sport has yet to be explored, particularly that which is inherent in the more mundane aspects of sport such as physical conditioning.

Why do athletes train? Why are there individuals who engage in regular physical training not for the purposes of competition, but for themselves? The experiential descriptions of these individuals will reveal commonalities of experience and hopefully a consensus of sorts upon the lived-world of intentional physical exercise; a consensus not clouded by concerns about competition or "goals" but based on the act of training - complete in itself.

\section{The Beginnings of Training}

My father was a runner, and a good runner ... he did a mile in 3:52 and that always impressed me ... but high school is where I really felt that it was an important thing to do and I think it started because I was rather heavy at that time.

If those damn kids can do it I can do it.

I was always intrigued by martial arts. I was looking for one that was different in the manner that it wasn't "hard-core." I felt a certain apprehension, but I wanted to follow it through.

We start our training lives with a positivistic attitude; we want to achieve observable results-a healthy body, a beautiful physique, a calm demeanor. The hidden riches buried deep within ourselves, that potential, that power-lies dormant and out of reach. We see an imperfect form, a rough shape-our "spadework" begins. That power, that lode, draws us inexorably. We find ourselves abandoning our natural inclinations to relax, to avoid pain and discomfort, to remain as we are. We allow ourselves to be "trailed, pulled along, dragged, drawn in, taken up" in the true sense of the word trahere, to train. We allow ourselves to be guided, to be drawn along the proper path, to be "brought up" in the sense that one "brings up" a child.

Why do we make this commitment to train, this commitment to struggle against what we are? When we submit to the training regimen we express our hope-sperere - "to look for, to expect." When we start to train we are initiating a search, with the expectation of finding. But finding what? A lovely body? Health? No. These tem- 
poral, observable goals are merely signposts, way-stations. Our training-search is a quest for a new being-in-the-world, a new sense of self. Through training we have the opportunity to mold-to recreate-ourselves. This is the "power" that is the epitomy of "fitness." Only the fit person gains the stamina and skill required to bend and prune the body, and we gain this fitness through the rigor of training.

The training quest is a difficult one. Early training experiences are characterized by impatience, frustration, pain, and a sense of despair - "Why doesn't my body work?" "What's wrong with me?" One needs hope to initiate training. But to carry through the training process, one needs faith as well. Faith-fidere-means "to trust, believe, to confide." One must believe in oneself. Training also requires fidelity, which, in the Latin, derives from fidei, referring not only to faith in oneself but to a belief in "credibility, actuality, fulfillment." When the person commits herself to "work out," she is keeping faith, in the sense that she has made a promise or given her word of honor.

It is not surprising, therefore, that the committed athlete approaches training with the utmost seriousness. It becomes, for her, a sacred ritual, a nobler form of play. As a consequence, the various aspects of the training routine are endowed with more significance than might normally be awarded to such activity (Huizinga, 1970).

\section{The Training Ritual}

There is a single-mindedness in the preparation to train; the dressing and the warmup become a private activity where the athlete draws into herself, preparing mentally for the training process-not unlike the medieval squire who maintains a silent nighttime vigil in the chapel before being knighted. It must be understood that the athlete is not "psyching" herself into the act of training: for the person who trains regularly there is no question about whether she will complete her training cycle. The athlete has "completed" her workout in her mind before she starts.

Training is work. It is continuous, repetitious, and rigorous. Training is not training without physical stress. Training is not "play"; it is not supposed to be "fun." For the Greeks, athletic training activities were "war games" in the literal sense. They were a preparation, a rehearsal, in that the activities were polished, refined, repeated over and over until there was that loss of consciousness about performing the activity - that point where the skill could be performed instinctively in the heat of battle.

For today's athlete the equivalent of "battle" is competition. The survival instinct is replaced by the will to win, to gain the prize. But 
what about the individual who trains but does not compete? The difficulties of training are compounded for the person who exercises without the pressure of "sudden death" either in athletic competition or warfare. She must "bring up" herself. The person is faced with the task of establishing goals to work towards; these goals do not exist except in her own mind. The individual who embarks upon a program of physical training without competing "exercises" in the truest sense of the word. She trains the body, the mind, and the spirit to battle obstacles that are not external, but internal. In the act of training, the athlete dares to hope, dares to experience life differently. In abandoning her old persona through training, the athlete gambles with her faith and her hope should she not succeed to reach those elusive riches, that motherlode.

The process of establishing-and achieving-goals in training, whether it be to run a four-minute mile or to swim eighty laps a day is a means of keeping faith with oneself, by making a promise-a vow-in the original sense of the word "faith." By keeping her vows the athlete reaffirms her hope - and the search continues. It is perhaps this "breaking of one's vows" that precipitates the "withdrawal" symptoms commonly experienced by athletes that are forced to break training.

There was a time in my running career where I ran every day-every day for, it must have been a stretch of four years-without missing a daynow that sounds absolutely bizarre ... I never missed ... and I do remember where I did miss one day and I had broken a four-year ritual, if you like, and a certain amount of depression set in ... I remember really going through withdrawal symptoms-sort of the notion that $I$ just couldn't get out ... not as if you're imprisoned, but that you've let yourself down.

Runners feel guilty ... it's a mental thing ... here you set a standard for yourself to run everyday and if you miss a day it's kind of a self-violation.

\section{Clothing as Ritual}

In order to maintain the training momentum, the athlete unconsciously searches for other aspects of the routine to "ritualize." Clothing that is worn by athletes becomes endowed with special properties; they become "vestments" in the sacrament of play (Huizinga, 1970).

I always used to wear the same sweater. It had to be the same sweater to the point where I would patch it up, if there were holes I'd sew them up ... I've always had an attachment to the running shoes I've had, the same running shoes... I would try to preserve them and keep them to the very, very limit... I remember the ritual to break in a new pair ... I would only wear them once, I would try to keep them special because I knew that they were going to get a battering eventually and end up like my old ones. 
Heidegger (1977) asks the question: how do we discover what a piece of equipment is? He answers this question by discussing "peasant shoes" as they appear in a painting by Van Gogh. The equipmental quality of equipment lies in its usefulness, its reliability. The more genuinely useful the equipment is, the less the person has to think about using (or wearing) the equipment-of being aware of it at all. He describes the nature of art as "the truth of being setting itself to work." The artwork is not the reproduction of something that actually exists, but the reproduction of the thing's general essence.

In a way, the athlete's clothes serve the same function as that of Van Gogh's paintings of peasant shoes. The battered training clothesthe worn running shoes, the swimsuit faded by chlorine, the sweatstained track suit, the holey, ravelled legwarmers-become a manifestation of the essence of training. A transubstantiation of sorts takes place (an extension of self, if you like); the athlete's clothes become the athlete's body - they endure the rigors of training just as the body itself receives punishment. In their "equipmental quality"-their reliability-the athlete, like the peasant woman, "is made privy to the silent call of the earth; by virtue of the reliability of the equipment she is sure of her world." Even athletes who have more than one set of training clothes have "favorite" clothes. When a training garment can no longer be worn because it has literally fallen apart, it is set aside with great reluctance.

I dig in the trunk at home from time to time and pull out bathing suits that are over ten years old. Too small and rotted away by chlorine and sweat, they cannot be worn, but they cannot be thrown away. Like Van Gogh's painting, they evoke that sense of secure familiarity. They are a part of my personal history; they are a part of me.

\section{The Training Space}

One characteristic of play/ritual is what Huizinga (1970) describes as "spatial separation" from everyday life. A space is set aside for the play activity, and within this play-space, certain rules are adhered to. Space, and "ownership" of territory, is very much a part of the training milieu, whether the training is being conducted in a swimming pool or on a running track in the river valley. Etiquette prevails.

In the swimming pool, for example, swimming up and down the lanes is done in a counter-clockwise direction. One is expected to keep a steady pace; sprinting and resting are frowned upon. Resting at the ends of the pool is met with equal disapproval, and standing in the middle of the lane is unheard of. If one is a slow swimmer, one is expected to allow faster swimmers to pass. "Dogging" a slower swimmer is considered bad manners; if a person wants to pass, a light tap of the person's foot with one hand usually causes the slower 
swimmer to permit the faster swimmer to pass. Faster swimmers generally have a stronger sense of space, or "territory," particularly when space is limited. For the athlete, the freedom to move without encumbrance allows the mind to forget about the mechanics of moving and allows the body to take over completely.

It means being in tune with your body ... it's a high, a feeling of completely being in control of yourself ... you're just tuned to yourself.

When an athlete finds his freedom to move interfered with, the euphoria of the training experience is lessened considerably. Often the frustration may lead to violence. Runners commonly relate stories about fistfights erupting on running trails where cross-country skiers and runners vie for space.

\section{People in Training}

The relationship that athletes share in the individual training milieu is generally one of tacit acceptance. Ideally the athlete would prefer to have the entire training space to herself in order to allow the mind-body to become "lost" through the freedom of movement. When the athlete is in a training environment that does not allow her this solitude, she may "use" the other athletes as a means of enhancing her training experience.

I'm only aware of other people when I'm overweight and in the sense that I perversely use other people to push myself to get into shape ... I'll run others so that I'm pushing myself.

To share the same training space is to share the energy of those around you, to be inextricably tied to the rhythm established in the environment by those in close proximity to you. Acquiescing to that rhythm of people in one's presence is a form of capitulation. "Setting the pace" becomes a power struggle.

If you don't let them go ahead, you'll keep their pace-they'll set the pace and they'll run you ragged ... you really draw into each other's presence, what they call Damitzein- "being with"-in German phenomenology, that you become a unit and if he's a more physically fit person he'll bring you along. ... It's an act of will to say "No, I'm not going to go with him."

In the individual training environment there is always a sense of competition on one level or another. There is an appraisal of the strength and skill of others present. People are categorized as "dilettantes," "social athletes," or "serious athletes" by the way they behave, by the clothes they wear, by the skill they possess. Once the pecking order is established people are expected to adhere to the unspoken rules of the environment; if one cannot keep the pace, they must let others set the pace. They must not interfere with the training of others. People who talk and "fool around" are not consid- 
ered "serious" and are not truly accepted by the training fraternity; neither are people who quit or take unscheduled rests in the course of a workout. Certain value judgments are made about the character of these individuals based on their training behavior.

I find someone who's running, you can see that they're really, really going after it, whatever that "after it" is, but they're going, they're travelling, they're into it, whereas "Joggers," well, they're sort of justjogging, they're sort of putting in time ... this may sound crass, but just sort of wiggling their ass, and that's all they're doing ... you know that a "jogger" won't keep it up.

The "dilettante" in the training environment is different from the serious athletes in terms of intent and commitment. The dilettante concerns herself with the externals-she appears to train-she appears to be athletic, but she does not have the commitment necessary to achieve the mind-body experience that athletes crave, an experience that is only accessible after the body has reached a certain level of mechanical efficiency and stamina. The dilettante is obsessed with the "trappings" of training. The clothes she wears are "appropriate" for the sport; by donning this costume she hopes to endow herself with a certain amount of integrity - or credibility, if you like. Unfortunately these clothes never acquire the reliability, the "equipmentality," of those belonging to the serious athlete, because they are primarily for show. They do not acquire a "character" from the individual's athletic endeavors; they remain unintegrated, separate and apart from the individual. When the dilettante "trains" she resembles a person at a costume party; she is "all dressed up and no place to go."

With this "external" orientation goes a certain way of being-in-theworld, in this case the training environment. Because the individual has not discovered the essence of training through doing, she is condemned to play at being an athlete. She sprints down the track or the swimming lane, she does elaborate warmups, she is an expert on the proper waxes to use on skis, she wears Danskins (and no other brand!)-she is happily caught up in the oblivion of external paraphernalia. She does not use the paraphernalia as equipment-as a means to an end-as serious athletes do. For her the paraphernalia is the end. The training-as-ritual exists for her only as far as she can do things with least resistance. The disciplina-the ordered way of life, the new way of viewing the world that comes through training, will never be achieved by the dilettante. She will never be able to touch her soul.

Charles Reich (1970) describes the preoccupation of contemporary individuals with the trappings of experience, who concern themselves with being "knowledgeable" or "competent" at something, but who never allow themselves to learn about the thing from the inside 
out. The activities they pursue are not integrated into a whole lifethey are dichotomized into soulless activities that are not part of that person's life in the sense that they are integral to his holistic well-being.

\section{From Training to Transcendence}

This writer suggests that there is a real danger that the athlete who trains may also lose touch with the training-essence, becoming engulfed by the monotony-the mechanical same-ness of the routine. The training regimen becomes businesslike; the athlete becomes stern, rigid. She becomes, in her fanaticism to train seriously, as sterile, and as holistically alienated, as the "dilettante." But training does not have to be a mechanized, technical activity devoid of emotional "highs." As the athlete toughens her body and submits to the rigors of the training schedule, her capitulation, her acceptance of these strictures eventually allows her a great deal of freedom. Her body is a superbly-functioning machine-it is "equipment," if you like. The training parameters are set, only to be broken should she desire to do so. All she must do is meet her minimum training level. So the athlete sets her limits farther every day. As the boundaries move farther away, the athlete moves further into unmapped territory, she looks over her shoulder at what she has left behind, and then she is drawn inexorably into the wilderness. She leaves familiar landmarks behind, she becomes anxious and frightened-she is in a strange place--but she keeps on going, deeper and deeper into the dark, it sucks her in, and the deeper she goes, she realizes that all of the old rules-the rules of life, death, experience, no longer apply-she goes further, nothing matters now, there is a lump in her throat, her body continues to move and there is no more pain, she reaches the other side of the darkness, intact, suffused with the sense of her own power, the triumph of life over fear. Leonard (1974) reflects upon this phenomenon in relating the experience of Roger Bannister:

One day I had been swimming, and to get warm I started running. Soon I was running across the moor to a distant part of the coast of Kintyre. It was near evening and fiery sun clouds were chasing over to Arran. It began to rain, and the sun shining brightly behind me cast a rainbow ahead. It gave me the feeling that I was cradled in the rainbow arc as I ran.

I felt I was running back to all the primitive joy that my season had destroyed. At the coast the rainbow was lost in the myriad particles of spray, beaten up by the breakers as they crashed vainly against the granite rocks. I grew calmer as I sat watching pebbles lazily rolling to and fro where the fury had gone from the waves. I turned back.

The gulls were crying overhead and a herd of wild goats were silhouetted against the headland. I started to run again with the sun in my eyes nearly blinding me. I could barely distinguish slippery rock from heath- 
ery turf or bog, yet my feet did not slip or grow weary now - they had new life and confidence. I ran in a frenzy of speed, drawn on by an unseen force. The sun sank, setting the forest ablaze, and turning the sky to dull smoke. Then tiredness came on and my bleeding feet tripped me. I rolled down a heather-topped bank and lay there happily exhausted. (Bannister, 1955)

It is in these moments, where one experiences that mind/body oneness, that total integration of body and soul where physical strictures disintegrate into nothingness-where the athlete can truly "play," where she can finally allow herself to "let things happen." In this ecstatic training netherworld the athlete revels in her strength, her freedom from the peccadilloes that dog her everyday existence. To reach these "outer limits," however, requires a surrender not only of the body but of the soul. This surrender is dependent upon the strength of the faith that has sustained the training-search. In that moment where the athlete reaches those outer boundaries, the point where rationality is abandoned, the individual comes closest to making the ultimate discovery (Leonard, 1974). The motherlode, the inner riches that are the destination of her search become, finally, within her grasp. As she reaches out to touch them, she becomes, at that moment, privy to the music of the spheres.

When things are going right you feel great ... it feels as if you could go on and on forever-you really feel quite confident and strong.... You feel like you'd be able to take on the Russian Army or something.

It's having the ability to go and go and go and go, and you're never quite sure where that end is, and you feel so good about it. You don't know quite where your end potential lies, that you continually think you can do better, continually think that you can refine it, and you don't know where that "end" is, where that final refinement will be, where you think you've reached your limit, whatever that is.

I sensed certainly a new power over myself . . that notion of being able to control myself at any given time.

In moments of pain and anxiety the athlete asks herself: How can I go on? Where is the edge? Will I go over? Can I go on after having been-here?

To play like this with pain that is unbearable yet is being borne, to summon up the presence of death itself, is to become a high-wire artist at some lofty place in human existence, one who balances precariously and triumphantly at the edge of unknown possibilities. A day without such interplay is incomplete. Ordinary human intercourse seems dull, mundane. There is that high, large place so easy to reach, so hard to bear, so fascinating. (Leonard, 1974)

The lasting residue of these transcendent training moments, after the individual returns from the netherworld to the realm of everyday matters, is a heightened awareness of the capability of the 
body - a sense of awe and wonder. Concomitant with this sense is a renewed faith in oneself apart from the training milieu. Problems diminish in size and obstacles seem less forbidding. The integration of mind and body for a few moments each day, that "peace-making" with the warring physical and spiritual elements of one's nature, leaves an afterglow of tolerance and optimism. Through getting reacquainted with that spiritual center through physical exercise, one learns to trust and like oneself again.

Why do people train? They train to gain a sense of the universe, a sense of the limitlessness of their own potential, that sense of power and freedom and ecstasy one feels when there is the realization that there are no boundaries, that one can do anything, that one can lose oneself in experience, can surrender one's rational being-in-theworld and come back, renewed and stronger than before. And the search continues:

What we run for we shall never reach, and that is the heart and glory of it. In the end, running is its own reward. It can never be justified. We run for the sake of running, nothing more. (Leonard, 1974)

This is the essence, the lived-world, of training.

It's the same feeling that someone explained to me when he bought a sports car and I said to him "Why do you need all of this horsepower?" And he replied, "It's just the knowledge of knowing you can do it."

\section{Notes}

1. A number of friends and colleagues shared their training experiences with me, which enabled me to complete this paper. The unacknowledged quotes through the course of this paper are attributable to these individuals.

Ed is an apprentice in the elevator trade. In his spare time he practices Tai Chi on a regular basis at a downtown club. John V. is a graduate student who combines his doctoral studies in Curriculum with daily running. Dr. John J. is a sessional art instructor who also runs. Donna is a graduate student in Educational Psychology and a former ballet pupil who works out regularly in a dance studio. Barry, a science student, works as a lifeguard at the University pools and swims and cycles in his free time.

\section{References}

Bannister, R. (1954). First four minutes. London: Putnam.

Huizinga, J. (1970). Homo ludens. London: Paladin Publishers.

Krell, D. F. (Ed.). (1977). Martin Heidegger: Basic writings. New York: Harper \& Row.

Leonard, G. (1974). The ultimate athlete. New York: Avon Books.

Reich, C. (1970). The greening of America. New York: Random House. 